\title{
Correlation Based Ridge Parameters in Ridge Regression with Heteroscedastic Errors and Outliers
}

\author{
A. V. Dorugade \\ Y C Mahavidyalaya, Halkarni, Tal-Chandgad, Kolhapur (MS) - 416552, India \\ adorugade@rediffmail.com
}

Received 10 August 2014

Accepted 20 September 2015

\begin{abstract}
This paper introduces some new estimators for estimating ridge parameter, based on correlation between response and regressor variables for ridge regression analysis. A simulation study has been made to evaluate the performance of proposed estimators based on the minimum mean squared error (MSE) criterion compared to ordinary least squares (LS) estimator and ordinary ridge regression (RR) estimator. The simulation studies demonstrated that the suggested estimators are superior to LS and RR estimators in ridge regression analysis with Heteroscedastic and/or correlated errors, outlier observations.
\end{abstract}

Keywords: Heteroscedasticity; Multicollinearity; Mean square error; Outlier; Ridge estimator.

2000 Mathematics Subject Classification: 62F07, 62J05

\section{Introduction}

The multiple regression model is the most widely used statistical tool applied in all most every discipline, hence estimation of unknown parameters is a common interest for many users. It is well known that ordinary least squares (LS) estimators are the best linear unbiased ones. However, if the objective of any study is to minimize some specific risk function, then other types of estimators perform better than the LS estimators. Also, in regression analysis, the presence of multicollinearity among independent variables is a common problem which exhibits serious undesirable effects on the analysis. Its one of the major consequence on ordinary least squares (LS) is that the estimator produces huge sampling variances which may result in the exclusion of significant coefficients from the model (see Farrar and Glauber 1967). To overcome multicollinearity various biased estimators were put forward in the literature.

The Ridge Regression (RR) estimator proposed by Hoerl and Kennard (1970) is the most popular biased estimator. The ridge regression became extremely popular in the seventies and eighties; see the survey in McDonald (2009). However, RR estimator has some disadvantages; mainly it is a nonlinear function of the ridge parameter (or biasing constant) $k$. This leads to complicated equations when selecting $k$. The formula is there, for this ridge parameter but it depends on the unknown parameters, so its determination in practice is not feasible. Many authors proposed different approximations for it. Each new suggestion was compared with and often declared victory over some existing ones, but there did not exist a large scale comparison between 
all known methods. The conventional wisdom is that no single method would be uniformly better than all the others. Also, as pointed out by Liu (2003) when there exits sever multicollinearity the ridge parameter $k$ selected for ridge regression may not fully remedy the problem of multicollinearity. On the other hand ridge regression approach has been studied by McDonald and Galarneau (1975), Lawless (1978), Gibbons (1981), Sarkar (1992), Saleh and Kibria (1993), Zhong and Yang (2007), Singh and Chaubey (1987), Batah et al. (2008), Yang and Chang (2010) and others to mention a few. Ridge Regression estimator has been the benchmark for almost all the estimators developed later in this context.

Many different techniques for estimating $k$ have been proposed or suggested by different researchers Hoerl et al. (1975), Lawless and Wang (1976), B. M. Kibria (2003), Khalaf and Shukur (2005), Alkhamisi and Shukur (2007), Muniz and Kibria (2009), Dorugade and Kashid (2010), Al- Hassan (2010), Muniz et al. (2012) to mention a few. Some of these estimators are uses application of eigen values and/or error variance $\sigma^{2}$. Correlation between the regressor plays an important role in detection of multicollinearity. With this application, in this article we try to introduce some estimators for $k$ based on only correlation coefficients $\left(r_{i}\right)$ between response and regressor variables. In the present literature related to ridge parameter most of the researchers compare superiority of their suggested estimators with other existing methods using well ridge estimator given by Hoerl and Kennard (1970) in terms of minimum MSE criterion. In the present work we evaluate the performances of our suggested estimators of $k$ using parameter estimation method given by Hoerl and Kennard (1970) in the presence of multicollinearity, outliers and Heteroscedastic random errors respectively.

This article is organized as follows: In Section 2, we define model and parameter estimation methods. In Section 3, we have proposed some new estimators for $k$ based on correlation coefficients $\left(r_{i}\right)$ between response and regressor variables. We compare that our new estimators in the mean square error (MSE) sense, to the RR estimator, in the same Section. In Section 4, Performances of the proposed estimators with respect to the scalar MSE criterion compare to LS and RR estimators are evaluated based on the Monte Carlo Simulation results. Finally, article ends with some concluding remarks.

\section{Model and Estimators}

Consider, widely used linear regression model

$$
Y=X \beta+\varepsilon,
$$

where $Y$ is a $n \times 1$ random vector of response variables, $X$ is a known $n \times p$ matrix with full column rank, $\varepsilon$ is the vector of errors $E(\varepsilon)=0$ and $\operatorname{Cov}(\varepsilon)=\sigma^{2} I_{n} . \beta$ is a $p \times 1$ vector of unknown regression parameters and $\sigma^{2}$ is the unknown variance parameter. For the sake of convenience, we assume that the matrix $X$ and response variable $Y$ are standardized in such a way that $X^{\prime} X$ is a non-singular correlation matrix and $X^{\prime} Y$ is the correlation between $X$ and $Y$.

Let $\Lambda$ and $T$ be the matrices of eigen values and eigen vectors of $X^{\prime} X$, respectively, satisfying $T^{\prime} X^{\prime} X T=\Lambda$ $=$ diagonal $\left(\lambda_{1}, \lambda_{2}, \ldots, \lambda_{p}\right)$, where $\lambda_{i}$ being the $i^{\text {th }}$ eigen value of $X^{\prime} X$ and $T^{\prime} T=T T^{\prime}=I_{p}$. We obtain the equivalent model

$$
Y=Z \alpha+\varepsilon,
$$

where $Z=X T$, it implies that $Z^{\prime} Z=\Lambda$, and $\alpha=T^{\prime} \beta$ (see Montgomery et al., 2003)

Then LS estimator of $\alpha$ is given by

$$
\hat{\alpha}_{L S}=\left(Z^{\prime} Z\right)^{-1} Z^{\prime} Y=\Lambda^{-1} Z^{\prime} Y .
$$

Therefore, LS estimator of $\beta$ is given by

$$
\hat{\beta}_{L S}=T \hat{\alpha}_{L S} .
$$




\subsection{Ridge Regression Estimator (RR)}

To overcome multicollinearity under ridge regression, Hoerl and Kennard (1970) suggested an alternative estimate by adding a ridge parameter $k$ to the diagonal elements of the least square estimator. It is given as:

$$
\hat{\alpha}_{R R}=\left[I-k(\Lambda+k I)^{-1}\right] \hat{\alpha}_{L S}
$$

Therefore, RR estimator of $\beta$ is given by

$$
\hat{\beta}_{R R}=T \hat{\alpha}_{R R}
$$

and mean square error of $\hat{\alpha}_{R R}$ is

$$
\operatorname{MSE}\left(\hat{\alpha}_{R R}\right)=\hat{\sigma}^{2} \sum_{i=1}^{p} \lambda_{i} /\left(\lambda_{i}+k\right)^{2}+k^{2} \sum_{i=1}^{p} \hat{\alpha}_{i}^{2} /\left(\lambda_{i}+k\right)^{2}
$$

where, $\hat{\alpha}_{i}$ is the $i^{\text {th }}$ element of $\hat{\alpha}_{L S}, \quad i=1,2, \ldots, p$ and $\hat{\sigma}^{2}$ is the LS estimator of $\sigma^{2}$ i.e. $\hat{\sigma}^{2}=\frac{Y^{\prime} Y-\hat{\alpha}_{L S}^{\prime} Z^{\prime} Y}{n-p-1}$.

Hoerl et al. (1975) suggested that, the value of ' $k$ ' is chosen small enough, for which the mean squared error of ridge estimator, is less than the mean squared error of LS estimator. Among the various methods here we used most widely used ridge parameter to compute $\hat{\alpha}_{R R}$ given by Hoerl et al. (1975) which given as below.

$$
k=p \hat{\sigma}^{2} / \sum_{i=1}^{p} \hat{\alpha}_{i}^{2}
$$

We observe that, when $k=0$ in Eq. (2.5), MSE of LS estimator of $\alpha$ is recovered. Hence

$$
\operatorname{MSE}\left(\hat{\alpha}_{L S}\right)=\hat{\sigma}^{2} \sum_{i=1}^{p} 1 / \lambda_{i}
$$

\section{Proposed Estimators}

Rodgers and Nicewander (1988) present a longer review of ways to interpret the correlation coefficient. They present 13 different ways of interpretations to conceptualize correlation coefficients as a most basic measure of bivariate relationship. Most of these interpretations are distribution free, since computation of a sample correlation requires no assumptions about a population (see Nefzger and Drasgow, 1957). Based on one of these interpretation, for the bivariate data $(X, Y)$ when we standardize the two raw variables, the standard deviations become unity and the slope of the regression line of $Y$ on $X$ as becomes the correlation coefficient. In this case, the intercept is 0 , and the regression line is easily expressed as $\hat{Y}=r X$

It is well known that the correlation coefficient between the regressor helpful in detecting the near linear dependency between the same pairs of regressor only. However, correlation between regressor plays an important role in detecting problem of multicollinearity. Based on the model defined in (2.1) we extend the interpretation in multiple linear regression and regression line can be expressed as

$$
\hat{Y}=X C
$$

Where, $C=\left(r_{1}, r_{2}, \ldots, r_{p}\right)^{\prime}$ with $r_{i}=r\left(Y, X_{i}\right) \quad i=1,2, \ldots, p$ is the vector of order $1 \times p$ of correlation coefficients. Now we introduce some estimators of $k$ based on $C$; since suggested estimators are based on correlation coefficients $r_{i}$ these are termed as correlation based estimators. We denote our ridge parameters by 
and

$$
\begin{gathered}
k_{c}(1)=A . M .\left(r_{i}\right), \\
k_{c}(2)=\operatorname{Median}\left(r_{i}\right)
\end{gathered}
$$

$$
k_{c}(3)=H \cdot M \cdot\left(r_{i}\right) .
$$

Even though the above approach is quite simple and straightforward, to the best of our knowledge, it has not been considered in the literature at all.

Based on these above estimators of ridge parameter $k$, using Eq. (2.4) estimators of $\alpha$ are given by

$$
\hat{\alpha}_{c}^{(j)}=\left[\Lambda+k_{c}(j) I\right]^{-1} Z^{\prime} Y, \quad j=1,2,3,
$$

or

$$
\hat{\alpha}_{c}^{(j)}=\left\lfloor I-k_{c}(j) A_{j}^{-1}\right\rfloor \hat{\alpha}_{L S}, \quad j=1,2,3,
$$

where, $A_{j}=\left(\Lambda+k_{c}(j) I\right)$ for $j=1,2,3$.

Hence, estimators of $\beta$ are:

$$
\hat{\beta}_{c}^{(j)}=T \hat{\alpha}_{c}^{(j)}, \quad j=1,2,3 .
$$

Thus, the coordinate wise estimators can be written as

$$
\hat{\alpha}_{c}^{(j)}=\left[\frac{\lambda_{i}}{\left(\lambda_{i}+k_{c}(j)\right)}\right] \hat{\alpha}_{i}, \quad j=1,2,3,
$$

where $\hat{\alpha}_{i}$ are the individual components of $\hat{\alpha}_{L S}$.

3.1. Bias, Variance and MSE of $\hat{\alpha}_{c}^{(j)}, j=1,2,3$

Bias of $\hat{\alpha}_{c}^{(j)}$ :

$$
\begin{aligned}
\operatorname{Bias}\left(\hat{\alpha}_{c}^{(j)}\right) & =E\left[\hat{\alpha}_{c}^{(j)}\right]-\alpha \\
& =-k_{c}(j) A_{j}^{-1} \alpha, \quad j=1,2,3 .
\end{aligned}
$$

Variance of $\hat{\alpha}_{c}^{(j)}$ :

$$
\begin{aligned}
\operatorname{Var}\left(\hat{\alpha}_{c}^{(j)}\right) & =E\left[\left(\hat{\alpha}_{c}^{(j)}-E\left(\hat{\alpha}_{c}^{(j)}\right)\right)\left(\hat{\alpha}_{c}^{(j)}-E\left(\hat{\alpha}_{c}^{(j)}\right)\right)^{\prime}\right] \\
& =\left(I-k_{c}(j) A_{j}^{-1}\right) \sigma^{2} \Lambda^{-1}\left(I-k_{c}(j) A_{j}^{-1}\right)^{\prime}, \quad j=1,2,3,
\end{aligned}
$$

where $\operatorname{MSE}\left(\hat{\alpha}_{L S}\right)=V\left(\hat{\alpha}_{L S}\right)=\sigma^{2}\left(Z^{\prime} Z\right)^{-1}=\sigma^{2} \Lambda^{-1}$.

MSE of $\hat{\alpha}_{c}^{(j)}$ :

$$
\begin{aligned}
\operatorname{MSE}\left(\hat{\alpha}_{c}^{(j)}\right) & =V\left(\hat{\alpha}_{c}^{(j)}\right)+\left[\operatorname{Bias}\left(\hat{\alpha}_{c}^{(j)}\right)\right]^{2} \\
& =\left(I-k_{c}(j) A_{j}^{-1}\right) \sigma^{2} \Lambda^{-1}\left(I-k_{c}(j) A_{j}^{-1}\right)^{\prime}+\left(k_{c}(j)\right)^{2} A_{j}^{-1} \alpha \alpha^{\prime} A_{j}^{-1}
\end{aligned}
$$

or

$$
\operatorname{MSE}\left(\hat{\alpha}_{c}^{(j)}\right)=\hat{\sigma}^{2} \sum_{i=1}^{p} \lambda_{i} /\left(\lambda_{i}+k_{c}(j)\right)^{2}+\left(k_{c}(j)\right)^{2} \sum_{i=1}^{p} \hat{\alpha}_{i}^{2} /\left(\lambda_{i}+k_{c}(j)\right)^{2}, \quad j=1,2,3,
$$

where, $\hat{\alpha}_{i}$ is the $i^{\text {th }}$ element of $\hat{\alpha}_{L S}, i=1,2, \ldots, p$. 


\subsection{Comparison Between the $\hat{\alpha}_{c}^{(j)}$ and $\hat{\alpha}_{R R}$}

It is well known that, the value of ridge parameter ' $k$ ' is chosen small enough, for which the mean squared error of RR estimator, is less than the mean squared error of LS estimator. Hence, in the following we only compare our proposed estimator to the RR estimator. Using Eq. (2.5) and Eq. (3.2) we investigate the following difference:

$$
\operatorname{MSE}\left(\hat{\alpha}_{R R}\right)-\operatorname{MSE}\left(\hat{\alpha}_{c}^{(j)}\right)=\sum_{i=1}^{p}\left[\frac{\left(\hat{\sigma}^{2} \lambda_{i}+k^{2} \hat{\alpha}_{i}{ }^{2}\right)}{\left(\lambda_{i}+k\right)^{2}}\right]-\sum_{i=1}^{p}\left[\frac{\left(\hat{\sigma}^{2} \lambda_{i}+\left(k_{c}(j)\right)^{2} \hat{\alpha}_{i}^{2}\right)}{\left(\lambda_{i}+k_{c}(j)\right)^{2}}\right], \quad j=1,2,3 .
$$

From above equation, it can be shown that

$$
\operatorname{MSE}\left(\hat{\alpha}_{R R}\right) \geq \operatorname{MSE}\left(\hat{\alpha}_{c}^{(j)}\right) \quad \text { for } j=1,2,3
$$

if and only if $\left(\lambda_{i}+k_{c}(j)\right)^{2}\left(\hat{\sigma}^{2} \lambda_{i}+k^{2} \hat{\alpha}_{i}^{2}\right) \geq\left(\hat{\sigma}^{2} \lambda_{i}+\left(k_{c}(j)\right)^{2} \hat{\alpha}_{i}^{2}\right)\left(\lambda_{i}+k\right)^{2}$.

\section{Simulation Study}

Consequently, parameter estimation methods are based on LS estimators do not assure the desirable results in the presence of multicollinearity, outliers and Heteroscedastic random errors respectively. Under these circumstances we evaluate the performance of proposed estimators compare to Least squares and ordinary ridge regression estimators through simulation study. We examined the average MSE (AMSE) of the $\hat{\beta}_{L S}, \hat{\beta}_{R R}$ and $\hat{\beta}_{c}^{(j)}$ estimators for different degrees of multicollinearity. We consider the true model as $Y=X \beta+\varepsilon$. Following McDonald and Galerneau (1975) the explanatory variables are generated by

$$
x_{i j}=\left(1-\rho^{2}\right)^{1 / 2} u_{i j}+\rho u_{i p}, \quad i=1,2, \ldots, n \quad j=1,2, \ldots, p .
$$

Where, $u_{i j}$ are independent standard normal pseudo-random numbers and $\rho$ is specified so that the theoretical correlation between any two explanatory variables is given by $\rho^{2}$. In this study, to investigate the effects of different degrees of multicollinearity on the estimators, we consider three different correlations, $\rho=0.85$, 0.95 and 0.99. $\beta$ parameter vectors are chosen arbitrarily for number of regressor $p=4$. The variance of the error terms is taken as $\sigma^{2}=3,10,25$ and 50. We assumed samples of size of 50,100 and 500. Estimators $\hat{\beta}_{L S}, \hat{\beta}_{R R}$ and $\hat{\beta}_{c}^{(j)}$ are computed and obtained the average MSE (AMSE) of estimators. The experiment is repeated 2000 times and computed $\operatorname{AMSE}(\hat{\beta})$ using the following expression.

$$
\operatorname{AMSE}(\hat{\beta})=\frac{1}{2000} \sum_{i=1}^{p} \sum_{s=1}^{2000}\left(\hat{\beta}_{i s}-\beta_{i}\right)^{2} .
$$

where, $\hat{\beta}_{i s}$ denote the estimator of the $i^{\text {th }}$ parameter in the $s^{\text {th }}$ replication and $\beta_{i}, i=1,2, \ldots, p$ are the true parameter values. We consider the method that leads to the minimum values of $\operatorname{AMSE}(\hat{\beta})$ to the best from the MSE point of view. The simulation is carried out for data exhibits with multicollinearity under following four different cases

a. Data generated using normal errors.

b. Data generated using outlier observations.

c. Data generated using Heteroscedastic errors.

d. Data generated using outlier observations and Heteroscedastic errors. 
Case (a): Here data exhibits with multicollinearity, generated using normal errors i.e. $\varepsilon \sim N\left(0, \sigma^{2} I_{n}\right)$. Firstly, we computed the $\operatorname{AMSE}(\hat{\beta})$ values using $\hat{\beta}_{L S}, \hat{\beta}_{R R}$ and $\hat{\beta}_{c}^{(j)}$ estimators for various values of triplet $(\rho$, $\mathrm{n}, \sigma^{2}$ ) for $p=4$ and reported in Table 1 .

From Table 1, we observe that performance of our proposed estimators $\hat{\beta}_{c}^{(j)}$ for $j=1,2,3$ is better than $\hat{\beta}_{L S}$ and $\hat{\beta}_{R R}$ for various values of triplet $\left(\rho, n, \sigma^{2}\right)$. Particularly for increasing value of the error variance $\sigma^{2}$, $\hat{\beta}_{c}^{(3)}$ gives smaller $A M S E$ values as compare to $\hat{\beta}_{c}^{(1)}$ and $\hat{\beta}_{c}^{(2)}$ estimators.

Case (b): The same simulation experiment as in case (a) is repeated for 2000 times for all combinations of $\rho, n$, and $\sigma^{2}$ by introducing respectively, one two and three outliers for $p=4$. We computed the $A M S E(\hat{\beta})$ using $\hat{\beta}_{L S}, \hat{\beta}_{R R}$ and $\hat{\beta}_{c}^{(j)}$ estimators for various values of combination $\left(\rho, n, \sigma^{2}\right)$ in the presence of outliers and reported in Table 2 .

Results in Table 2, shows that not only $\hat{\beta}_{L S}$ but also $\hat{\beta}_{R R}$ estimators are sensitive to the outlier observations. At the same time AMSE values of suggested estimators $\hat{\beta}_{c}^{(j)}$ for $j=1,2,3$ are significantly smaller compare to $\hat{\beta}_{L S}$ and $\hat{\beta}_{R R}$ estimators for all combinations of $\rho, n, \sigma^{2}$ and introduced number of outliers one, two and three, respectively. Among suggested estimators $\hat{\beta}_{c}^{(3)}$ gives smaller $A M S E$ values as compare to $\hat{\beta}_{c}^{(1)}$ and $\hat{\beta}_{c}^{(2)}$ estimators for increasing value of the error variance $\sigma^{2}$.

Case (c): Here we consider the problem of Heteroscedasticity. Means we assume that the elements of the random vector $\varepsilon$ were not independent and identically distributed random variables. To introduce Heteroscedastic and/or correlated errors in the model given in (2.2) and finally converted into in the following model

$$
\widetilde{Y}=\widetilde{Z} \alpha+\widetilde{\varepsilon},
$$

where, $\widetilde{Y}=P Y, \widetilde{\varepsilon}=P \varepsilon$ and $\widetilde{Z}=P Z$.

With the assumptions $E(\varepsilon)=0$ and $\operatorname{Cov}(\varepsilon)=\sigma^{2} V$, where $V$ is a known $\mathrm{n} \times \mathrm{n}$ symmetric positive definite (pd) matrix there exists a nonsingular symmetric matrix $P$ such that $V^{-1}=P^{\prime} P$ and $\sigma^{2}>0$ is the unknown variance parameter. Model given in (4.1) matrix $V$ will be estimated by method suggested by Firinguetti (1989). In the present study we choose $\rho=0.95$ and consider matrix $V$ is estimated as below

$$
V=\frac{1}{1-\rho^{2}}\left[\begin{array}{cccc}
1 & \rho & \ldots & \rho^{n-1} \\
\rho & 1 & \ldots & \rho^{n-2} \\
\cdot & \cdot & \cdot & \cdot \\
\cdot & \cdot & \cdot & \cdot \\
\cdot & \cdot & \cdot & \cdot \\
\rho^{n-1} & \rho^{n-2} & \ldots & 1
\end{array}\right]
$$

We computed the $\operatorname{AMSE}(\hat{\beta})$ using $\hat{\beta}_{L S}, \hat{\beta}_{R R}$ and $\hat{\beta}_{c}^{(j)}$ estimators for various values of combination $(\rho, \mathrm{n}, \mathrm{V}$, $\sigma^{2}$ ) for $p=4$ and reported in Table 3 .

From Table 3, we observe that performance of our estimators $\hat{\beta}_{c}^{(j)}$ for $j=1,2,3$ is better than $\hat{\beta}_{L S}$ and $\hat{\beta}_{R R}$ when data exhibits with multicollinearity generated using Heteroscedastic and/or correlated errors. In this case also, for increasing value of the error variance $\sigma^{2}, \hat{\beta}_{c}^{(3)}$ gives smaller AMSE values as compare to $\hat{\beta}_{c}^{(1)}$ and $\hat{\beta}_{c}^{(2)}$ estimators. 
Case (d): In this case we evaluate the performance of proposed estimators for the simulated data exits with not only outliers but also Heteroscedastic and/or correlated errors, in linear regression model in the presence of multicollinearity. We introduce respectively one, two and three outliers in the simulated data with Heteroscedastic and/or correlated errors, where Heteroscedastic and/or correlated errors are introduced using the same method as given in Case (c). For the simulated data sets we computed the $\operatorname{AMSE}(\hat{\beta})$ using $\hat{\beta}_{L S}$, $\hat{\beta}_{R R}$ and $\hat{\beta}_{c}^{(j)}$ estimators for $p=4$ and values are reported in Table 4.

From AMSE values reported in Table 4, we observe that even if data exits with multicollinearity simulated with Heteroscedastic and/or correlated errors and having outlier observation in it, estimators $\hat{\beta}_{c}^{(j)}$ for $j=1,2,3$ gives better performance than $\hat{\beta}_{L S}$ and $\hat{\beta}_{R R}$. As same in case (a) to (c) as value of the error variance $\sigma^{2}$ has increases, $\hat{\beta}_{c}^{(3)}$ gives smaller $A M S E$ values as compare to $\hat{\beta}_{c}^{(1)}$ and $\hat{\beta}_{c}^{(2)}$ estimators.

From Case (a) to (d) in above simulation study, It is observed that $\hat{\beta}_{L S}$ produces estimators of $\beta$ with large values of the $\operatorname{AMSE}(\hat{\beta})$ in each of the above cases from (a) to (d) as compare to $\hat{\beta}_{R R}$ and $\hat{\beta}_{c}^{(j)}$ estimators. Whereas proposed estimators $\hat{\beta}_{c}^{(j)}$ for $j=1,2,3$ are better as compare to $\hat{\beta}_{L S}$ and $\hat{\beta}_{R R}$ estimators, since these estimators produces smaller values of the $\operatorname{AMSE}(\hat{\beta})$ in each of the above cases (a) to (d) for different combinations of size of the sample (n), level of multicollinearity $(\rho)$, variance of the error term $\left(\sigma^{2}\right)$, number of predictors $(\mathrm{p})$, matrix $\mathrm{V}$ and introduced outlier observations. Overall, $\hat{\beta}_{c}^{(3)}$ gives better performance among the proposed estimators in all the cases. The novel feature of the proposed estimator is that it can be used without any modification in the proposed estimator it is better alternative to combat one or more than one problems among multicollinearity, outliers and Heteroscedastic and/or correlated errors occurs in linear regression.

\section{Conclusion}

In this article some new estimators of ridge parameter $k$ and hence biased estimators $\hat{\beta}_{c}^{(j)}, j=1,2,3$, for estimating $\beta$ in linear regression are introduced. The investigation of proposed estimators has been done using Monte Carlo experiments, where levels of correlation, the numbers of explanatory variables and the sample sizes have been varied. The evaluation of our estimators has been done by comparing the MSEs of our proposed estimators with the LS estimator and the estimators of Hoerl and Kennard (1970). We found that our estimators uniformly dominate the other estimators in ridge regression analysis with outliers and Heteroscedastic and/or correlated errors. We believe that the findings of this paper will be useful for the practitioners.

\section{Acknowledgements}

The author wish to thank the anonymous referee for his/her comments and the editor which improved the original version. The present studies were supported in part Research Award Scheme by UGC, India Project No. F. 30-1/2014/RA-2014-16-GE-MAH-5958 (SA-II). 
Table 1. AMSE of LS and other estimators $\left(p=4\right.$ and $\left.\beta=(10,3,7,1)^{\prime}\right)$

\begin{tabular}{|c|c|c|c|c|c|c|c|c|c|c|c|c|c|c|c|}
\hline & $\begin{array}{l}E \\
8 \\
0\end{array}$ & $\begin{array}{l}\circ \\
8 \\
8 \\
8\end{array}$ & $\begin{array}{l}8 \\
\infty \\
\infty \\
0 \\
-1\end{array}$ & 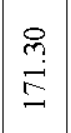 & $\begin{array}{l}\stackrel{m}{m} \\
\ddot{v}\end{array}$ & $\begin{array}{l}\stackrel{P}{2} \\
\dot{0} \\
\stackrel{D}{\sim} \\
\stackrel{\sim}{N}\end{array}$ & 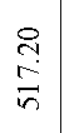 & $\begin{array}{l}\stackrel{9}{1} \\
\stackrel{9}{-}\end{array}$ & 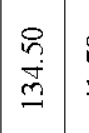 & $\begin{array}{c}\infty \\
\stackrel{\infty}{\forall} \\
\vec{\forall}\end{array}$ & 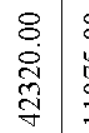 & $\begin{array}{l}8 \\
\dot{0} \\
\hat{0} \\
=\end{array}$ & $\begin{array}{l}\infty \\
\infty \\
\dot{\sigma} \\
\dot{\sigma}\end{array}$ & $\stackrel{\infty}{\underset{\sim}{q}}$ & $\begin{array}{l}\hat{0} \\
\dot{8}\end{array}$ \\
\hline & $\begin{array}{l}0 \\
\stackrel{0}{0} \\
\stackrel{0}{0}\end{array}$ & $\begin{array}{l}\infty \\
\vdots \\
\vdots \\
\sigma \\
\sigma\end{array}$ & $\begin{array}{l}\stackrel{8}{\circ} \\
\dot{i}\end{array}$ & 尽 & $\stackrel{\vec{m}}{\vec{n}}$ & 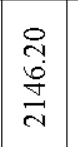 & $\begin{array}{l}8 \\
\stackrel{8}{0} \\
0\end{array}$ & $\stackrel{?}{\stackrel{i}{i}}$ & $\begin{array}{l}8 \\
\dot{\lambda} \\
\end{array}$ & 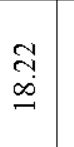 & $\begin{array}{l}8 \\
\infty \\
\infty \\
\infty \\
\infty \\
-\infty\end{array}$ & $\begin{array}{l}\dot{8} \\
\dot{m} \\
\stackrel{8}{2}\end{array}$ & 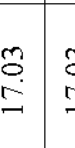 & $\stackrel{m}{\Xi}$ & 尺્ \\
\hline & $\begin{array}{l}0 \\
\infty \\
\varnothing \\
0\end{array}$ & $\begin{array}{l}0 \\
\infty \\
0 \\
0 \\
\end{array}$ & $\stackrel{8}{\circ}$ & $\begin{array}{l}n \\
\infty \\
\infty\end{array}$ & $\stackrel{\Xi}{\Xi}$ & $\begin{array}{l}8 \\
\\
8 \\
\end{array}$ & $\begin{array}{l}\stackrel{8}{\circ} \\
\dot{\infty}\end{array}$ & $\begin{array}{l}\stackrel{8}{N} \\
\infty \\
-\infty\end{array}$ & 尺) & $\begin{array}{l}\infty \\
\stackrel{\infty}{\infty} \\
\infty\end{array}$ & $\begin{array}{c}\stackrel{8}{8} \\
\stackrel{\sim}{J} \\
\underset{\sim}{J}\end{array}$ & $\begin{array}{l}8 \\
\stackrel{8}{0} \\
\frac{1}{n}\end{array}$ & సે & $\stackrel{\text { ते }}{=}$ & $\begin{array}{l}\stackrel{8}{\circ} \\
\text { in }\end{array}$ \\
\hline & $\stackrel{n}{\stackrel{n}{c}}$ & $\stackrel{ }{\stackrel{9}{r}}$ & $\stackrel{8}{\square}$ & 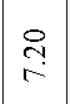 & $\frac{?}{2}$ & $\begin{array}{l}8 \\
\stackrel{+}{\forall}\end{array}$ & $\stackrel{8}{\stackrel{n}{=}}$ & $\begin{array}{l}8 \\
\infty \\
\infty\end{array}$ & $\begin{array}{c}8 \\
\infty \\
\infty\end{array}$ & 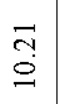 & $\begin{array}{l}8 \\
8 \\
8 \\
0\end{array}$ & 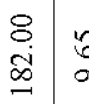 & $\begin{array}{l}b \\
a \\
a\end{array}$ & bo & ڤ̊ \\
\hline \multirow{4}{*}{5} & 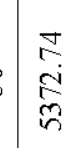 & $\begin{array}{l}\infty \\
\stackrel{\infty}{\dot{D}} \\
\stackrel{\infty}{-}\end{array}$ & 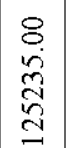 & $\begin{array}{l}\stackrel{g}{g} \\
\stackrel{+}{a} \\
\stackrel{2}{\sim}\end{array}$ & $\begin{array}{l}\underset{i}{1} \\
\infty \\
\infty\end{array}$ & 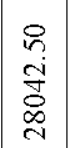 & $\begin{array}{l}0 \\
0 \\
0 \\
0 \\
0 \\
0\end{array}$ & $\begin{array}{l}\stackrel{P}{2} \\
\stackrel{2}{2} \\
\stackrel{5}{5}\end{array}$ & 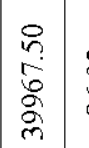 & $\begin{array}{l}\tilde{O} \\
\dot{0} \\
\dot{\infty}\end{array}$ & \begin{tabular}{l|l}
8 & \\
0 & \\
0 & 0 \\
0 & \\
0 &
\end{tabular} & 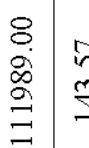 & 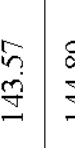 & $\begin{array}{l}\stackrel{\partial}{\infty} \\
\dot{J} \\
\dot{J}\end{array}$ & $\begin{array}{l}8 \\
\text { \&. } \\
\text {. }\end{array}$ \\
\hline & $\begin{array}{l}\infty \\
\stackrel{\infty}{0} \\
\stackrel{\infty}{\Omega}\end{array}$ & $\begin{array}{l}n \\
\tilde{d} \\
\infty \\
\infty\end{array}$ & $\begin{array}{c}\stackrel{8}{8} \\
\dot{\vec{m}} \\
\underline{h}\end{array}$ & $\begin{array}{l}\stackrel{8}{\mathrm{I}} \\
\mathrm{U} \\
=\end{array}$ & $\begin{array}{l}0 \\
0 \\
0 \\
0\end{array}$ & 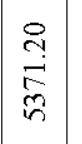 & 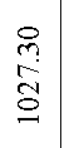 & $\begin{array}{l}\circ \\
\stackrel{1}{2}\end{array}$ & $\begin{array}{l}8 \\
8 \\
2\end{array}$ & $\begin{array}{l}\mathcal{f} \\
\stackrel{8}{n} \\
i n\end{array}$ & 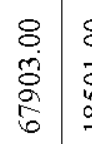 & \begin{tabular}{l|l}
8 & \\
& 0 \\
$\infty$ & 0 \\
$\infty$ &
\end{tabular} & $\begin{array}{l}5 \\
\text { ò } \\
\text { n. }\end{array}$ & $\begin{array}{l}\infty \\
0 \\
0 \\
0 \\
\end{array}$ & $\begin{array}{l}\infty \\
\infty \\
\dot{m}\end{array}$ \\
\hline & $\begin{array}{l}5 \\
0 \\
0 \\
m\end{array}$ & $\begin{array}{l}\underset{Z}{U} \\
ٍ \\
=\end{array}$ & $\underset{\dot{i}}{\stackrel{8}{2}}$ & $\begin{array}{l}8 \\
\stackrel{0}{1}\end{array}$ & $\begin{array}{l}\infty \\
\infty \\
\infty \\
\infty\end{array}$ & 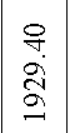 & 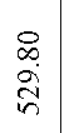 & $\begin{array}{l}\circ \\
\stackrel{2}{2}\end{array}$ & 8 & $\begin{array}{l}\stackrel{\sim}{\sim} \\
\stackrel{\sim}{\sim}\end{array}$ & 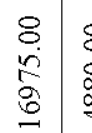 & $\begin{array}{ll}8 & \\
\dot{8} & = \\
\infty & \\
\stackrel{\infty}{\sigma} & =\end{array}$ & $\begin{array}{l}\vec{F} \\
\dot{g} \\
\vec{g}\end{array}$ & 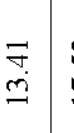 & $\stackrel{n}{=}$ \\
\hline & $\begin{array}{l}n \\
m \\
i n\end{array}$ & $\begin{array}{l}\vec{D} \\
\dot{\vec{v}}\end{array}$ & $\underset{\infty}{\stackrel{8}{\infty}}$ & $\stackrel{2}{2}$ & $\frac{2}{a}$ & 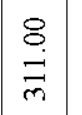 & $\begin{array}{l}0 \\
\infty \\
\infty \\
\infty\end{array}$ & $\begin{array}{l}8 \\
0 \\
0\end{array}$ & $\stackrel{8}{8}$ & $\stackrel{n}{\hat{\sigma}}$ & $\begin{array}{l}8 \\
\stackrel{8}{\dot{d}} \\
\stackrel{्}{\tilde{C}}\end{array}$ & 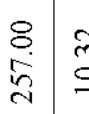 & 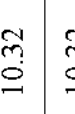 & ભొ & $\stackrel{?}{\stackrel{9}{=}}$ \\
\hline & $\begin{array}{l}n \\
\infty \\
\infty \\
\infty \\
\infty\end{array}$ & 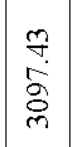 & 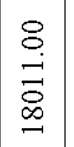 & $\begin{array}{l}0 \\
\infty \\
\infty \\
o \\
0 \\
0\end{array}$ & $\begin{array}{l}\stackrel{\overbrace{}}{2} \\
\stackrel{0}{\circ} \\
\stackrel{\sim}{\sim}\end{array}$ & 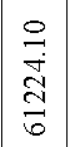 & 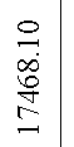 & $\begin{array}{l}8 \\
8 \\
y \\
\forall \\
\forall\end{array}$ & 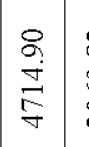 & 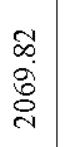 & 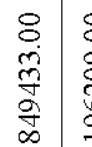 & 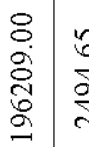 & 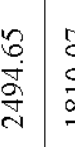 & $\begin{array}{l}\hat{\delta} \\
\dot{0} \\
\infty \\
-\end{array}$ & $\begin{array}{l}\infty \\
\stackrel{0}{0} \\
\text { mै }\end{array}$ \\
\hline & 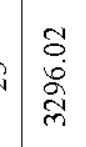 & $\begin{array}{l}\mathscr{D} \\
\infty \\
\dot{\infty} \\
⿱ 亠\end{array}$ & $\begin{array}{l}8 \\
\stackrel{8}{0} \\
\dot{8}\end{array}$ & \begin{tabular}{l}
$\stackrel{2}{a}$ \\
\hdashline \\
$i$
\end{tabular} & $\begin{array}{l}\overrightarrow{\ddot{q}} \\
\dot{q}\end{array}$ & $\mid \begin{array}{l}8 \\
\stackrel{8}{2} \\
\ddot{3}\end{array}$ & $\begin{array}{l}\stackrel{\ominus}{0} \\
\ddot{8} \\
\stackrel{8}{8}\end{array}$ & $\begin{array}{l}\stackrel{\circ}{ } \\
\stackrel{m}{=}\end{array}$ & 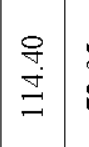 & 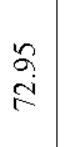 & 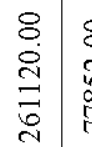 & $\begin{array}{l}8 \\
\mathbb{1} \\
\infty \\
0 \\
5\end{array}$ & 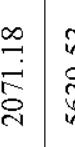 & $\begin{array}{l}\tilde{n} \\
\hat{n} \\
\hat{2} \\
i\end{array}$ & $\begin{array}{l}\text { ิㅗㅇ } \\
\text { S. }\end{array}$ \\
\hline & 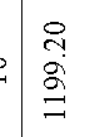 & 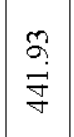 & $\begin{array}{l}\stackrel{8}{8} \\
\text { I }\end{array}$ & $\begin{array}{l}\stackrel{p}{m} \\
\dot{v}\end{array}$ & $\begin{array}{l}\text { ర్ } \\
\infty \\
\infty \\
\sim\end{array}$ & $\begin{array}{l}0 \\
n \\
8 \\
8 \\
m \\
m\end{array}$ & $\begin{array}{l}8 \\
\dot{0} \\
\infty \\
\infty\end{array}$ & $\begin{array}{l}8 \\
\text { i } \\
\text { m }\end{array}$ & $\frac{\AA}{m}$ & $\begin{array}{l}\stackrel{8}{0} \\
\text { mे }\end{array}$ & 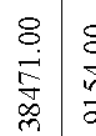 & $\begin{array}{l}8 \\
\dot{0} \\
\frac{5}{2}\end{array}$ & 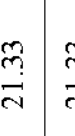 & $\stackrel{m}{\vec{v}}$ & $\begin{array}{l}n \\
\ddot{j} \\
\ddot{j}\end{array}$ \\
\hline & $\begin{array}{l}1 \\
1 \\
0 \\
0 \\
0 \\
\end{array}$ & $\begin{array}{l}8 \\
\ddot{8} \\
\ddot{7}\end{array}$ & $\stackrel{8}{\Xi}$ & 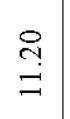 & $\begin{array}{l}\circ \\
\stackrel{2}{3}\end{array}$ & $\begin{array}{l}0 \\
\infty \\
\infty \\
\infty \\
0\end{array}$ & $\begin{array}{l}8 \\
\stackrel{n}{5} \\
\stackrel{+}{0}\end{array}$ & $\begin{array}{l}8 \\
\circ \\
0\end{array}$ & $\begin{array}{l}8 \\
\stackrel{0}{9}\end{array}$ & 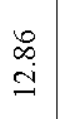 & $\begin{array}{l}8 \\
\stackrel{9}{0} \\
\infty \\
\infty\end{array}$ & 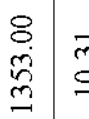 & $\vec{m}$ & $\vec{m}$ & $\stackrel{\infty}{=}$ \\
\hline 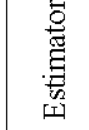 & 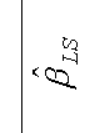 & $\cos ^{\frac{2}{2}}$ & $\tilde{C}_{0}$ & $\begin{array}{l}0 \\
0 \\
0\end{array}$ & $\begin{array}{l}\hat{0} \\
<0\end{array}$ & $\cos ^{\frac{1}{2}} 0^{-1}$ & $e^{\frac{2}{20}}$ & $\hat{\sigma}_{0} 0$ & $\hat{\Omega}_{0} 0$ & $\hat{\Omega}_{0} 0$ & $x_{0}^{2} 0^{\frac{1}{2}} \mid<$ & $\left\langle Q^{\frac{\alpha}{2}}=B_{0}\right.$ & $E_{0} 0 \Omega$ & $e_{0}^{\circ}$ & $\widehat{\hat{B}}$ \\
\hline$a$ & & & & & & & & 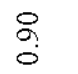 & & & & & gे & & \\
\hline
\end{tabular}


Table 2. AMSE of LS and other estimators $\left(p=4, \rho=0.95\right.$ and $\left.\beta=(15,1,2,6)^{\prime}\right)$

\begin{tabular}{|c|c|c|c|c|c|c|c|c|c|c|c|c|c|}
\hline in & \begin{tabular}{|c|}
8 \\
0 \\
0 \\
0 \\
0 \\
$\infty$
\end{tabular} & $\begin{array}{l}8 \\
8 \\
0 \\
0 \\
0 \\
0\end{array}$ & $\begin{array}{l}8 \\
\tilde{n} \\
\alpha\end{array}$ & $\begin{array}{l}\stackrel{8}{-} \\
\overrightarrow{-}\end{array}$ & $\begin{array}{l}\vec{\infty} \\
\infty \\
\infty \\
\infty\end{array}$ & 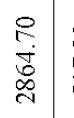 & $\begin{array}{l}\stackrel{i}{1} \\
\stackrel{\vec{n}}{n}\end{array}$ & \begin{tabular}{l|l}
9 & \multicolumn{1}{c}{} \\
$\dot{0}$ & $\bar{J}$ \\
&
\end{tabular} & 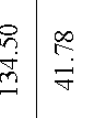 & $\begin{array}{l}8 \\
\dot{\Xi} \\
\stackrel{\mathbb{J}}{y} \\
\text { y }\end{array}$ & 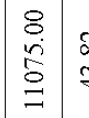 & \begin{tabular}{l|l}
$\tilde{S}$ & $\infty$ \\
$\dot{\sigma}$ & $\stackrel{m}{q}$
\end{tabular} & 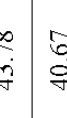 \\
\hline$\ddot{i}$ & \begin{tabular}{|l|}
8 \\
8 \\
0 \\
0 \\
$\infty$ \\
-1
\end{tabular} & 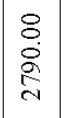 & $\begin{array}{l}8 \\
\infty \\
\infty\end{array}$ & $\begin{array}{l}8 \\
\infty \\
\infty\end{array}$ & $\stackrel{g}{g}$ & 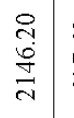 & \begin{tabular}{l|l}
8 & 0 \\
0 & 1 \\
0 & 7
\end{tabular} & 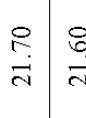 & 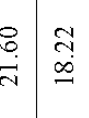 & $\begin{array}{c}8 \\
\dot{\infty} \\
\infty \\
\infty \\
\infty \\
-1\end{array}$ & $\begin{array}{l}8 \\
\dot{0} \\
\dot{m} \\
\dot{8} \\
1\end{array}$ & $\begin{array}{c}0 \\
\stackrel{0}{=}\end{array}$ & $\underset{c}{a}=$ \\
\hline$\stackrel{\circ}{1}$ & \begin{tabular}{|l|}
8 \\
\\
$\dot{1}$ \\
$\stackrel{2}{2}$ \\
\end{tabular} & $\begin{array}{l}8 \\
\\
\dot{8} \\
\stackrel{8}{8} \\
\end{array}$ & 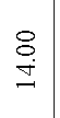 & $\begin{array}{l}8 \\
\dot{\square}\end{array}$ & $\begin{array}{c}\text { ले } \\
\text { 它 }\end{array}$ & $\begin{array}{l}8 \\
8 \\
0 \\
0\end{array}$ & \begin{tabular}{l|l}
$\stackrel{8}{0}$ & $\delta$ \\
$\dot{\infty}$ & 0
\end{tabular} & 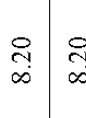 & 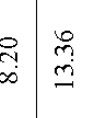 & $\mid \begin{array}{c}\mathcal{O} \\
\mathbb{J} \\
\mathbb{J}\end{array}$ & $\begin{array}{ll}\dot{8} \\
\dot{0} \\
\dot{\vec{n}}\end{array}$ & $\stackrel{\text { શે }}{=} \stackrel{\text { શે }}{=}$ & 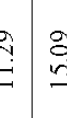 \\
\hline in & $\begin{array}{l}8 \\
\dot{0} \\
\stackrel{0}{0} \\
=\end{array}$ & 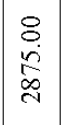 & $\begin{array}{l}8 \\
\infty\end{array}$ & $\begin{array}{l}8 \\
\infty \\
\infty\end{array}$ & 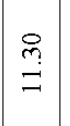 & 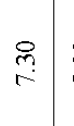 & \begin{tabular}{l|l}
8 \\
in
\end{tabular} & \begin{tabular}{c|c}
8 \\
\hdashline
\end{tabular} & \begin{tabular}{c|c}
$\delta_{0}$ & $\vec{n}$ \\
$\alpha$
\end{tabular} & $\begin{array}{l}8 \\
8 \\
0 \\
0 \\
-1\end{array}$ & $\begin{array}{l}8 \\
\dot{8} \\
i n\end{array}$ & \begin{tabular}{l|l}
$\vec{b}$ & $\vec{\circ}$ \\
$\circ$ & $\circ$
\end{tabular} & \begin{tabular}{l|l}
$\overrightarrow{0}$ \\
0
\end{tabular} \\
\hline in & \begin{tabular}{l}
8 \\
8 \\
0 \\
0 \\
0 \\
0 \\
\hdashline
\end{tabular} & 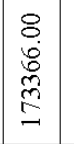 & $\begin{array}{l}8 \\
\dot{8} \\
n\end{array}$ & $\begin{array}{l}8 \\
\circ \\
\circ\end{array}$ & 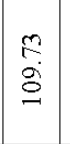 & 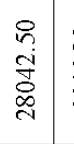 & \begin{tabular}{c|c}
0 & $\wp$ \\
0 & 0 \\
0 & 0 \\
0 & 8 \\
0 & 1
\end{tabular} & 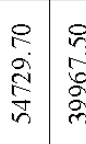 & 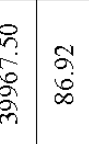 & \begin{tabular}{|l|}
8 \\
0 \\
0 \\
0 \\
0 \\
0 \\
0
\end{tabular} & $\begin{array}{l}8 \\
\dot{0} \\
\dot{0} \\
\stackrel{0}{0} \\
\Xi \\
\Xi\end{array}$ & 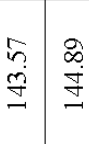 & $\begin{array}{l}0 \\
\dot{f} \\
\\
\end{array}$ \\
\hline 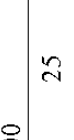 & $\begin{array}{l}8 \\
0 \\
0 \\
0 \\
0 \\
0\end{array}$ & \begin{tabular}{|c|}
8 \\
$\dot{I}$ \\
$\mathbb{D}$ \\
$\infty$ \\
$\infty$ \\
$\infty$
\end{tabular} & $\begin{array}{l}8 \\
\dot{+} \\
\vec{y} \\
\qquad\end{array}$ & $\begin{array}{l}8 \\
0 \\
\stackrel{\infty}{1} \\
\infty \\
-1\end{array}$ & $\begin{array}{c}\bar{J} \\
\stackrel{m}{g} \\
\stackrel{9}{-}\end{array}$ & 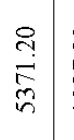 & 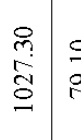 & $\begin{array}{cc}9 & 8 \\
2 & 0 \\
2 & 0\end{array}$ & 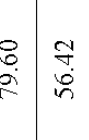 & $\begin{array}{l}8 \\
0 \\
0 \\
0 \\
0 \\
0\end{array}$ & $\begin{array}{c}\dot{O} \\
\dot{\vec{D}} \\
\dot{\infty} \\
\stackrel{\infty}{-}\end{array}$ & 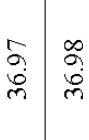 & 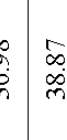 \\
\hline 으 & 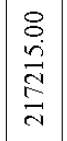 & $\begin{array}{l}8 \\
\stackrel{8}{0} \\
\stackrel{0}{0} \\
\stackrel{0}{\sigma} \\
\end{array}$ & $\begin{array}{l}8 \\
: \\
\circ\end{array}$ & $\begin{array}{l}\stackrel{8}{0} \\
\dot{\square} \\
\end{array}$ & 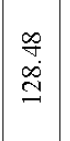 & 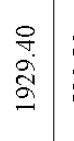 & 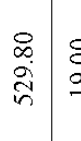 & $\begin{array}{l}8 \\
\vdots \\
\vdots\end{array}$ & 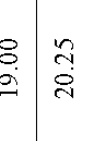 & 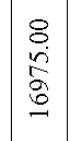 & $\begin{array}{c}8 \\
\dot{0} \\
\dot{0} \\
\dot{\infty} \\
\dot{\infty}\end{array}$ & 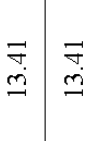 & $\begin{array}{l}\overrightarrow{2} \\
\hat{2}\end{array}$ \\
\hline in & 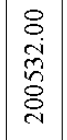 & $\begin{array}{l}8 \\
\dot{n} \\
n \\
m \\
m\end{array}$ & $\begin{array}{l}\stackrel{8}{\circ} \\
\stackrel{m}{m}\end{array}$ & $\begin{array}{l}\stackrel{8}{i} \\
\text { స్ }\end{array}$ & $\begin{array}{l}\overrightarrow{0} \\
\dot{\Xi} \\
\stackrel{0}{0}\end{array}$ & $\begin{array}{c}\stackrel{\circ}{-} \\
\overrightarrow{0}\end{array}$ & $\begin{array}{c}m \\
m\end{array}$ & \begin{tabular}{l|l}
$n$ \\
\hdashline \\
\hdashline
\end{tabular} & 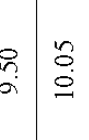 & $\begin{array}{l}8 \\
\dot{0} \\
0 \\
\end{array}$ & $\begin{array}{l}8 \\
0 \\
9 \\
9\end{array}$ & \begin{tabular}{c|c|c}
$\mathscr{\infty}$ & $\mathscr{\sigma}$ \\
$\sigma$ & $\sigma$
\end{tabular} & \begin{tabular}{l}
$\vec{y}$ \\
\hdashline \\
\hdashline
\end{tabular} \\
\hline in & $\begin{array}{l}8 \\
\circ \\
\dot{0} \\
0 \\
0 \\
0 \\
0\end{array}$ & 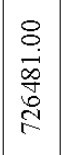 & $\begin{array}{l}8 \\
\dot{\vec{D}} \\
0\end{array}$ & $\begin{array}{l}8 \\
\overleftarrow{i} \\
0 \\
0\end{array}$ & 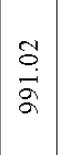 & $\begin{array}{l}\stackrel{O}{\dot{j}} \\
\underset{\mathbb{Z}}{b} \\
\end{array}$ & 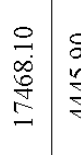 & 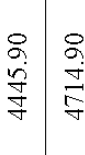 & 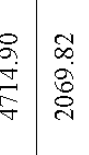 & \begin{tabular}{|c|} 
\\
$\dot{b}$ \\
$\dot{m}$ \\
$\dot{\sigma}$ \\
$\dot{\sigma}$ \\
$\infty$
\end{tabular} & 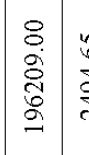 & 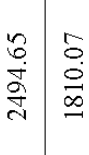 & $\begin{array}{l}\infty \\
\stackrel{0}{0} \\
\text { mे }\end{array}$ \\
\hline$i$ & 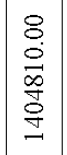 & 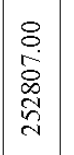 & $\begin{array}{l}\stackrel{8}{0} \\
\dot{\vec{m}} \\
\dot{m}\end{array}$ & $\begin{array}{l}8 \\
\stackrel{8}{0} \\
\text { o }\end{array}$ & \begin{tabular}{l}
8 \\
$:$ \\
0 \\
\hdashline
\end{tabular} & $\begin{array}{l}8 \\
\stackrel{0}{3} \\
\hat{b}\end{array}$ & 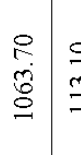 & 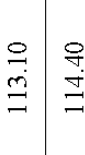 & 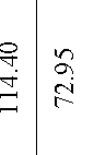 & 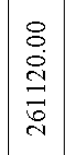 & 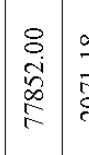 & 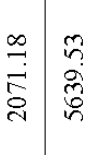 & 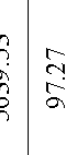 \\
\hline 응 & $\begin{array}{l}\stackrel{8}{0} \\
\infty \\
\tilde{\delta} \\
\stackrel{0}{\sigma} \\
\stackrel{0}{-}\end{array}$ & 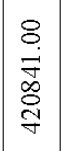 & $\begin{array}{l}8 \\
\infty \\
\infty \\
5\end{array}$ & $\begin{array}{l}8 \\
\stackrel{1}{1} \\
\stackrel{0}{-}\end{array}$ & $\begin{array}{l}\infty \\
\infty \\
0 \\
\dot{\sigma} \\
0\end{array}$ & $\begin{array}{l}0 \\
0 \\
0 \\
0 \\
0 \\
0\end{array}$ & $\begin{array}{ll}8 & 8 \\
\infty & 0 \\
\infty & 0\end{array}$ & \begin{tabular}{c|c}
$\stackrel{\circ}{0}$ \\
m
\end{tabular} & \begin{tabular}{l|l}
$\stackrel{a}{0}$ \\
$\dot{m}$
\end{tabular} & 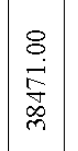 & $\begin{array}{l}8 \\
\dot{5} \\
\stackrel{5}{\sigma}\end{array}$ & $\stackrel{m}{\vec{N}} \underset{\sim}{\stackrel{\sim}{N}}$ & 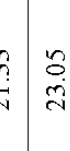 \\
\hline $\begin{array}{l}n \\
11 \\
\text { "b }\end{array}$ & 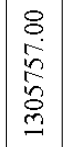 & 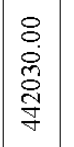 & $\begin{array}{l}8 \\
\stackrel{.}{\vec{m}} \\
\stackrel{\sim}{m}\end{array}$ & $\begin{array}{l}8 \\
\stackrel{0}{0} \\
\overrightarrow{0} \\
\stackrel{0}{0}\end{array}$ & $\begin{array}{l}0 \\
\text { i } \\
\text { d. }\end{array}$ & $\begin{array}{l}\stackrel{8}{9} \\
\stackrel{9}{\exists}\end{array}$ & 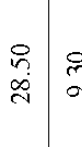 & 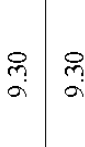 & 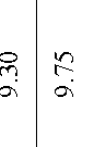 & 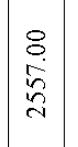 & $\begin{array}{l}8 \\
0 \\
\vdots \\
\alpha\end{array}$ & 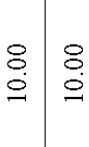 & ?े \\
\hline 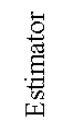 & $\cos ^{2 / 2}$ & 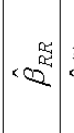 & 畣 & 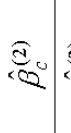 & 童 & $x^{2} 0^{2} \mid x$ & 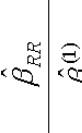 & $\begin{array}{c}\theta_{0} \\
0\end{array}$ & $\begin{array}{l}\bar{s} \\
0 \\
0\end{array}$ & $\cdot 0^{\frac{1}{2}}$ & $<0^{2} \mid<0^{2}$ & $\begin{array}{ll}\hat{C}_{0} \\
0\end{array}$ & 200 \\
\hline 䇾 & & & $\frac{8}{\stackrel{0}{0}}$ & & & & & $\frac{0}{11}$ & & & & 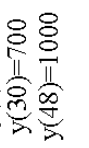 & \\
\hline
\end{tabular}


Table 3. AMSE of LS and other estimators $\left(p=4\right.$ and $\left.\beta=(6,3,4,2)^{\prime}\right)$

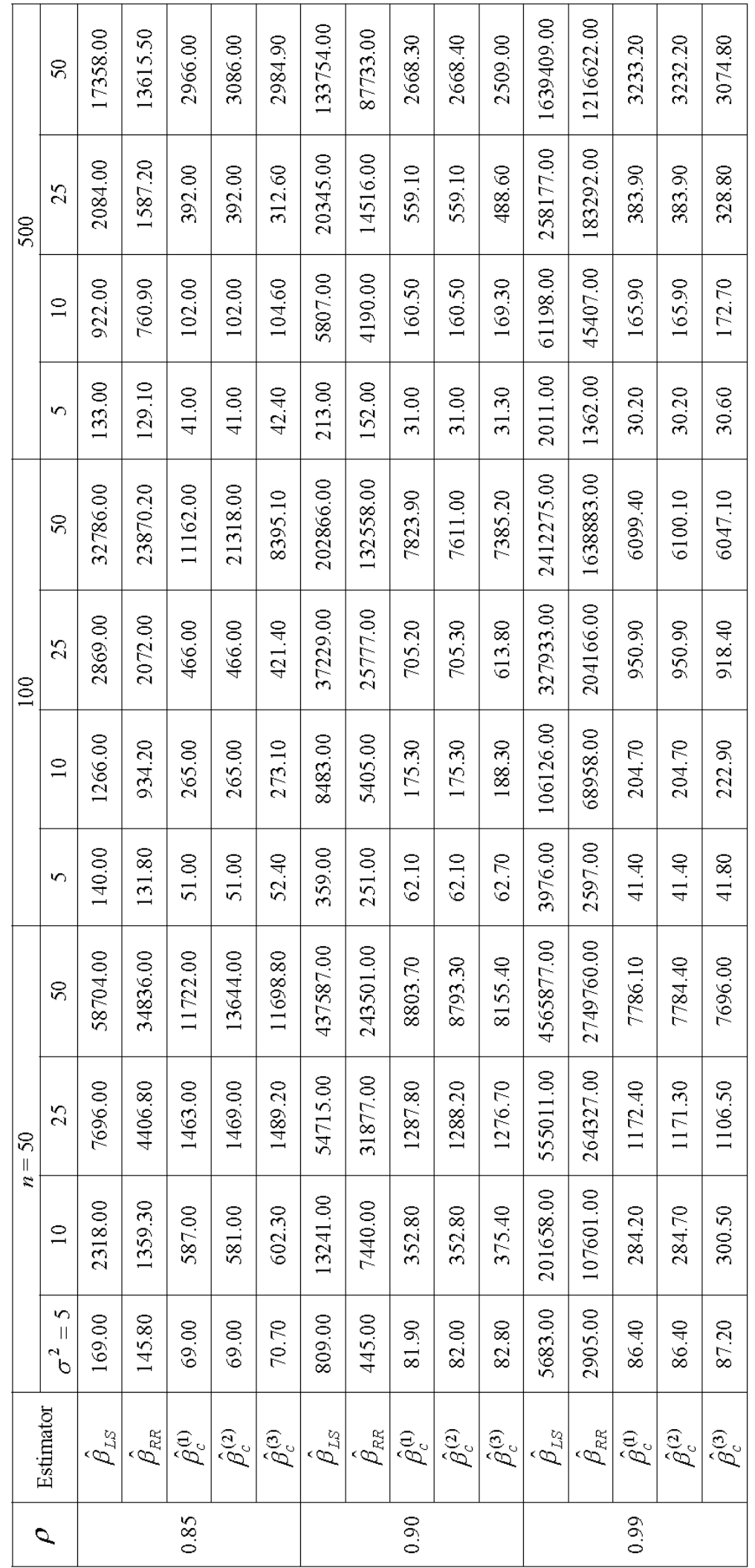


Table 4. AMSE of LS and other estimators $\left(p=4, \rho=0.95\right.$ and $\left.\beta=(4,9,3,3)^{\prime}\right)$

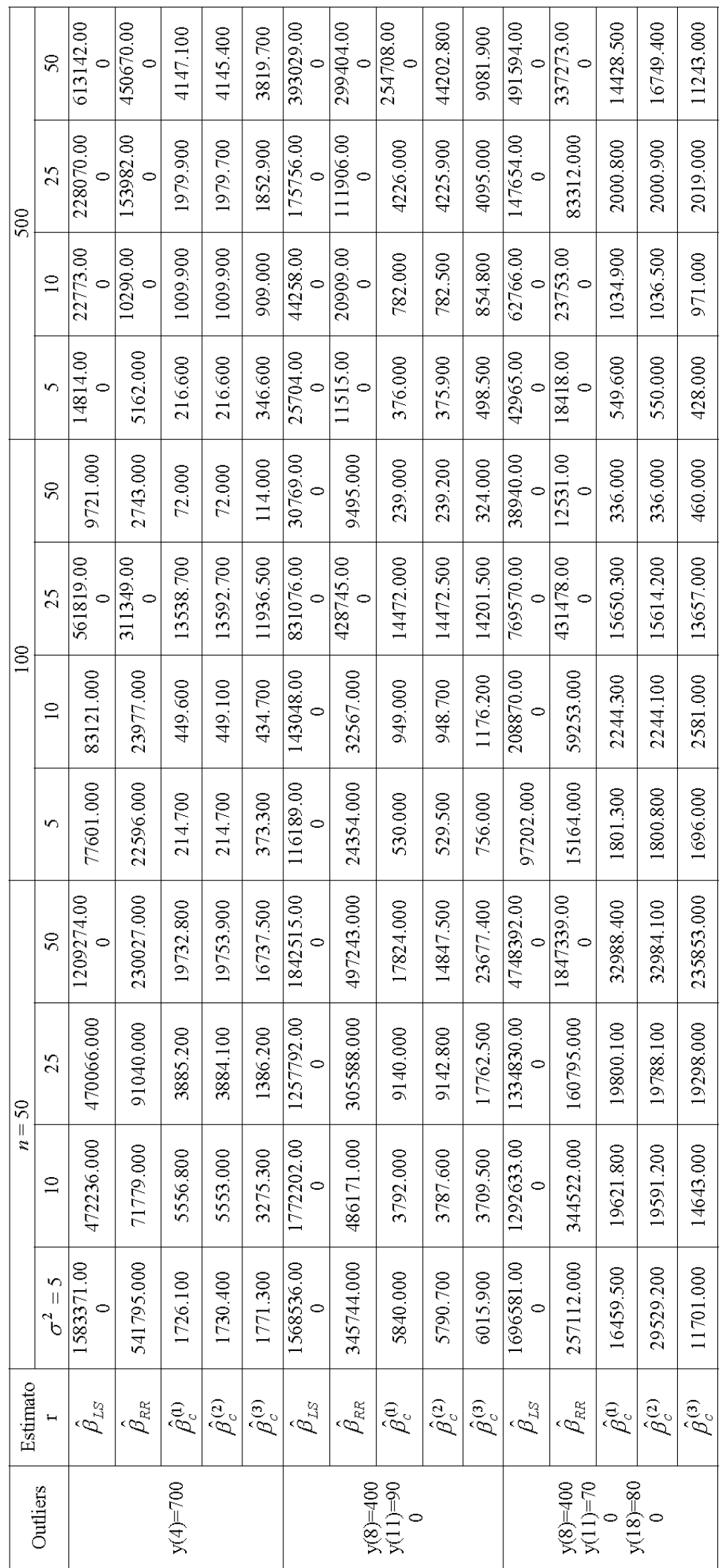




\section{References}

[1] D.E. Farrar and R.R. Glauber, Multicollinearity in regression analysis: The problem revisited, The Review of Economics and Statistics, 49(1), (1967), 92-107.

[2] A.E. Hoerl and R.W. Kennard, Ridge regression: Biased estimation for non-orthogonal problems, Technometrics, 12, (1970), $55-67$.

[3] G. C. McDonald, (2009) Ridge regression. Wiley Interdisciplinary Reviews, Computational Statistics, 1, (2009), 93-100.

[4] K. J. Liu, Using Liu-type estimator to combat collinearity, Communications in Statistics-Theory and Methods, 32, (2003), 10091020.

[5] G. C. McDonald and D. I. Galarneau, A monte carlo evaluation of some ridge-type estimators. J. Amer. Statist. Assoc., 70, (1975), 407-416.

[6] J.F.Lawless, Ridge and related estimation procedure, Comm. Statist., 7, (1978), 139-164.

[7] D.G. Gibbons, A simulation study of some ridge estimators, J. Amer. Statist. Assoc., 76, (1981),131-139.

[8] N. Sarkar, A new estimator combining the ridge regression and the restricted least squares method of estimation, Comm. Statist., 21,(1992),1987-2000.

[9] A.K.Md.E.Saleh and B.M.G. Kibria, Performances of some new preliminary test ridge regression estimators and their properties, Comm. Statist., 22, (1993), 2747-2764.

[10] Z. Zhong and H.Yang, Ridge estimation to the restricted linear model, Comm. Statist. Theory Methods, 36, (2007), $2099-2115$.

[11] B. Singh and Y. P. Chaubey, On some improved ridge estimators, Statistical Papers, 28, (1987), 53-67.

[12] F.S.Batah, T. Ramnathan and S.D. Gore, The efficiency of modified jackknife and ridge type regression estimators: a comparison, Surveys in Mathematics and its Applications, 24(2), (2008), 157-174.

[13] H. Yang and X. Chang, A New Two-Parameter Estimator in Linear Regression, Comm. Statist. Theory Methods, 39, (2010), 923-934.

[14] A.E. Hoerl, R.W. Kennard and K.F. Baldwin, Ridge regression: Some simulations analysis. Commun. Statist., 4, (1975),105123.

[15] J.F. Lawless and P. Wang, A Simulation study of ridge and other regression estimators, Communications in Statistics -Theory and Methods, 14 (1976), 1589-1604.

[16] B.M.G. Kibria and A.K.Md.E.Saleh , Preliminary test ridge regression estimators with Student's $t$ errors and conflicting teststatistics. Metrika, 59, (2004), 105-124.

[17] G. Khalaf, and G. Shukur, Choosing ridge parameter for regression problem, Communications in Statistics.-Theory and Methods 34, (2005), 1177-1182.

[18] M.A. Alkhamisi, G. Shukur, A Monte carlo study of recent ridge parameters, Commun. Statist. -Simulation, 36 (3), (2007), 535 547.

[19] G. Muniz and B. M. G. Kibria, On some ridge regression estimators: An Empirical Comparisons, Communications in StatisticsSimulation and Computation, 38, (2009), 621-630.

[20] A.V. Dorugade and D. N. Kashid, Alternative method for choosing ridge parameter for regression, International Journal of Applied Mathematical Sciences, 4(9), (2010), 447 - 456.

[21] Y. Al-Hassan, Performance of new ridge regression estimators, Journal of the Association of Arab Universities for Basic and Applied Science, 9, (2010), 23-26.

[22] G. Muniz and B. M. G. Kibria, M. Kristofer and G. Shukur, On Developing Ridge Regression Parameters: A Graphical investigation, SORT-Statistics and Operations Research Transactions, 36 (2), (2012), 115-138.

[23] D.C. Montgomery, E.A. Peck and G.G. Vining, Introduction to Linear Regression Analysis, (Wiley), (2003).

[24] J.L. Rodgers and W.A. Nicewander, Thirteen Ways to Look at the Correlation Coefficient, The American Statistician, 42(1), (1988), 59-66.

[25] M. D. Nefzger, J. Drasgow, The Needless Assumption of Normality in Pearson's $r$, The American Psychologist, 12, (1957), 623625.

[26] L. A. Firinguetti, Simulation study of ridge regression estimators with autocorrelated Errors, Commun. Statist. Simulation and Computation, 18, (1989), 673-702. 